This document was prepared in conjunction with work accomplished under Contract No. DE-AC09-96SR18500 with the U.S. Department of Energy.

This work was prepared under an agreement with and funded by the U.S. Government. Neither the U. S. Government or its employees, nor any of its contractors, subcontractors or their employees, makes any express or implied: 1 . warranty or assumes any legal liability for the accuracy, completeness, or for the use or results of such use of any information, product, or process disclosed; or 2 . representation that such use or results of such use would not infringe privately owned rights; or 3 . endorsement or recommendation of any specifically identified commercial product, process, or service. Any views and opinions of authors expressed in this work do not necessarily state or reflect those of the United States Government, or its contractors, or subcontractors. 


\section{Chemical Storage: Myths vs. Reality}

Fred Simmons, SRS, David Quigley, Y-12, Helena Whyte, LANL, Janeen Robertson, LLNL, David Freshwater, SAIC, Lydia Boada-Clista, Ohio DOE, JC Laul, LANL

\section{$\underline{\text { Introduction }}$}

A large number of resources explaining proper chemical storage are available. These resources include books, databases/tables, and articles that explain various aspects of chemical storage including compatible chemical storage, signage, and regulatory requirements. Another source is the chemical manufacturer or distributor who provides storage information in the form of icons or color coding schemes on container labels. Despite the availability of these resources, chemical accidents stemming from improper storage, according to recent reports (1) (2), make up almost $25 \%$ of all chemical accidents. This relatively high percentage of chemical storage accidents suggests that these publications and color coding schemes although helpful, still provide incomplete information that may not completely mitigate storage risks. This manuscript will explore some ways published storage information may be incomplete, examine the associated risks, and suggest methods to help further eliminate chemical storage risks.

\section{Compatible Chemical Storage Methods}

Compatibility is the subject that gets the most attention during discussions of chemical storage. The two methods most commonly cited as a cure to solve incompatibility storage issues is to provide a listing of compatibilities by chemical class or to provide a compatibility listing by chemical. A third method that is not usually cited in the literature is to use the manufacturer's compatibility scheme. All three methods have their limitations.

\section{Compatibility Listings by Chemical Class}

A common approach used to define chemical compatibilities for storage purposes comes from determining each chemical's class and then determining the proper compatibility group based upon that class from a table. Tables of compatibilities groupings include the U.S. Coast Guards Cargo Compatibility Chart (3), the U. S. Environmental Protection Agency (EPA) Method 600 Compatibility Chart (4) which was ultimately used as the basis for the National Oceanic and Atmospheric Administration (NOAA) Chemical Reactivity Worksheet (5), and a multitude of "Home-Grown" charts tailored to the needs of the specific location. While the approach to classify chemical compatibilities by chemical class appears at first glance to be a good method that can be used to ensure compatible chemical storage, it is, in fact, only marginally better than storing chemicals alphabetically. There are several reasons for this. 
The first reason this method can create hazardous situations is that most chemicals belong to more than one hazard class which can lead to confusion as to which class is appropriate for the chemical in question. For example, nitric acid is both an acid and an oxidizer. If one stores it as an acid, then there is the potential that it will be stored with organic acids such as acetic or formic acid, which, if mixed, can lead to a significant adverse reaction. Acetic acid is not only an acid, but is also combustible liquid. Storing it with flammable liquids such as methanol would not be a problem. It should be noted that many compatibility schemes state that organic acids are incompatible with alcohols, but this is rarely the case.

A second reason why storage schemes based upon hazard classes are prone to failure is that some hazard classes are not listed. Sulfuric acid is a strong mineral acid, but it is also a strong dehydrating agent. Few, if any, classification schemes include dehydration as a chemical class and yet it can be significant. If one were inadvertently mixed another strong acid such as hydrofluoric or hydrochloric acid with sulfuric acid, the sulfuric acid would immediately dehydrate the hydrochloric or hydrofluoric acid. The result of this reaction would be a large amount of heat generation and the immediate off gassing of either hydrogen chloride or hydrogen fluoride due to the removal of water as a solvent.

A third reason classification schemes do not work well is because not all chemicals in a given class are compatible. Sodium dichloroisocyanurate and calcium hypochlorite are both oxidizers and belong to no other class of chemical, yet the mixing of these two materials can lead to the formation of nitrogen trichloride, a shock sensitive explosive (National Fire Protection Association (NFPA) 49, Hazardous Chemicals Data, 2001, p134).

A fourth reason why classification schemes do not work well is that they do not lend themselves toward consistent application between work areas. If a worker spends part of his time in a work area where nitric acid is defined as an oxidizer and the rest of his time where nitric acid is classed as an inorganic acid, then the worker can become confused as to which storage practice is used in which area. Confusing storage schemes can lead to unsafe storage practices.

A last reason why classification schemes do not work well is that they are based upon chemical classes such as esters, aromatic amines, non-oxidizing mineral acids, etc. While this classification scheme may be interpretable by a chemist, most workers are not chemists and would find these classifications confusing. Some classes such as nonoxidizing mineral acid could even confuse a chemist when the conditions present will determine whether an acid, such as sulfuric acid, is an oxidizer or not. As confusion increases, so does the potential for a mistake.

\section{$\underline{\text { Chemical Storage Listings }}$}

Another method in use to ensure compatible chemical storage is to use compatibility listings or charts. These documents list various chemicals and those chemicals with which they are compatible. Some, such as the American Chemical Society (ACS) 
publication Safety in Academic Laboratories (6), are fairly short, while others are more extensive. The primary difficulty with using these lists/charts is that they are limited. None provide information for every chemical or chemical product and, many times, some incompatible interactions are not noted. If one were to rely upon one of these charts, then it might provide a false sense of security if one assumes the listing is comprehensive. Another difficulty with these charts is that one does not always know the type of interaction or the conditions being described which cause the mixture to be incompatible nor is the applicability always apparent. For example, dilute solutions of analytical reagents made up in dilute acids and bases may not represent a significant incompatibility even though the listing indicates that it would be. A last issue concerning the difficulty in using these lists is that their use requires a certain amount of expertise and different users will have differing opinions as to how the listings should be applied. Variations in expertise or differences in opinion can lead to inconsistent applications of the storage scheme, which could become a problem if workers move from one work location to another.

\section{$\underline{\text { Manufacturer's Storage Schemes }}$}

Blindly using manufacturer's schemes can also lead to incompatible storage situations or storage situations that potentially violate regulations. Two well known manufacturer's or distributors of chemicals have similar color coded storage schemes. In both schemes, the color red is used to denote flammable storage, white is used to denote acid storage and yellow is used to denote oxidizer storage. If one looks at how various acids are classified according to these two schemes, one can immediately see numerous issues (Table 1).

\begin{tabular}{|l|l|l|l|}
\hline \multicolumn{2}{|c|}{ Manufacturer 1 } & \multicolumn{2}{c|}{ Manufacturer 2 } \\
\hline \multicolumn{1}{|c|}{ Chemical } & Compatibility Code & \multicolumn{1}{c|}{ Chemical } & Compatibility Code \\
\hline Hydrofluoric Acid & White & Hydrofluoric Acid & White \\
\hline Sulfuric Acid & White & Sulfuric Acid & White \\
\hline Hydrochloric Acid & White & Hydrochloric Acid & White \\
\hline Phosphoric Acid & White & Phosphoric Acid & White \\
\hline Oxalic Acid & White & Oxalic Acid & White \\
\hline Formic Acid & White & Formic Acid & White \\
\hline Acetic Acid & Red & Acetic Acid & Red \\
\hline Nitric Acid & Yellow & Nitric Acid & White \\
\hline Perchloric Acid & Yellow & Perchloric Acid & White \\
\hline
\end{tabular}

Table 1. Storage classification of acids using two similar manufacturer's storage schemes.

One issue that is readily observable is that incompatibilities exist within each storage scheme. Both manufacturers indicate that sulfuric acid can be stored compatibly with hydrochloric acid or hydrofluoric acid which has been shown not to be the case (see above). Additionally, Manufacturer 2 indicates that nitric and perchloric acids are compatible with formic and oxalic acids which is clearly untrue. Both manufacturers 
recommended acetic acid be stored as a flammable liquid while neither recommended it for formic acid. Both formic and acetic acids are classified as combustible liquids. This may require them to be stored in flammable liquids storage cabinets depending on the quantity of material on-hand and the limits imposed on the facility by codes or standards.

A second issue is that these two systems appear to be similar, but it would take a well trained individual to realize that they are different and what those differences are. If no compatibility scheme exists or the user is relying upon the manufacturer to provide the compatibility information on each chemical container, then using chemicals from more than one manufacturer could lead to incompatible chemical storage as the worker gets the various schemes confused.

A third issue in using the manufacturer's storage scheme is that most locations do not limit the chemicals present to those offered or classified by one manufacturer. If no other compatibility scheme exists, then how does one store a chemical that is not classified by the manufacturer?

A last issue to be cautious about when using a manufacturer's compatibility scheme is that they are not designed to address regulations which set facility limits on the quantity of specific chemicals that may be stored. For example, OSHA in 29CFR 1910.106 "Flammable and combustible liquids" or locally enforced fire codes such as NFPA 1 "Uniform Fire Code" (see below) limit how much of a flammable or combustible liquid may be stored in various locations such as outside of a flammable liquids storage cabinet. Storing organic acids that are not identified as being a flammable or combustible liquid could cause one to become noncompliant with flammable and combustible liquids storage requirements.

\section{Other Chemical Storage Considerations}

Storage areas are rarely discussed to any depth in chemical safety references. When they are discussed, topics such as provisions for bonding and grounding of flammable liquids, separation distances, storage unit (i.e. shelves or cabinet) types, or ventilation are usually covered. Several other important issues are rarely, however, covered.

\section{Compatibility}

When discussing compatibility the issue is usually exclusively limited to compatibilities between chemicals being stored. What is just as important is the issue of compatibility of chemicals being stored with their environment. Examples of improper storage conditions would include:

- Storage of oxidizers on unpainted wooden, shelves is prohibited (for example, NFPA 432 Code for the Storage of Organic Peroxide Formulations, 2002 Edition (7) also prohibits the storage of hydrogen peroxide [concentrations greater than $27.5 \%$ ] on wooden pallets since oxidizer impregnated wood is prone to spontaneously catching fire) (see Figure 1). 
- Chemicals should not be stored above face level due to the potential of spills falling into a person's face (see Figure 2).

- Storage of water reactive chemicals in a facility with a water-based fire suppression system (due to potentially adverse chemical reactions during a fire response),

- Corrosives stored on unpainted shelves (since corrosion which can weaken shelves or hydrogen gas generation can occur) (see Figure 3),

- Acid storage in rooms with unpainted cement floors and/or cement or concrete block walls (due to the reaction between acids and cement), and

- Oxidizers cannot be stored where they will come into contact with heating units, piping or ducts (since some oxidizers will violently decompose upon heating).

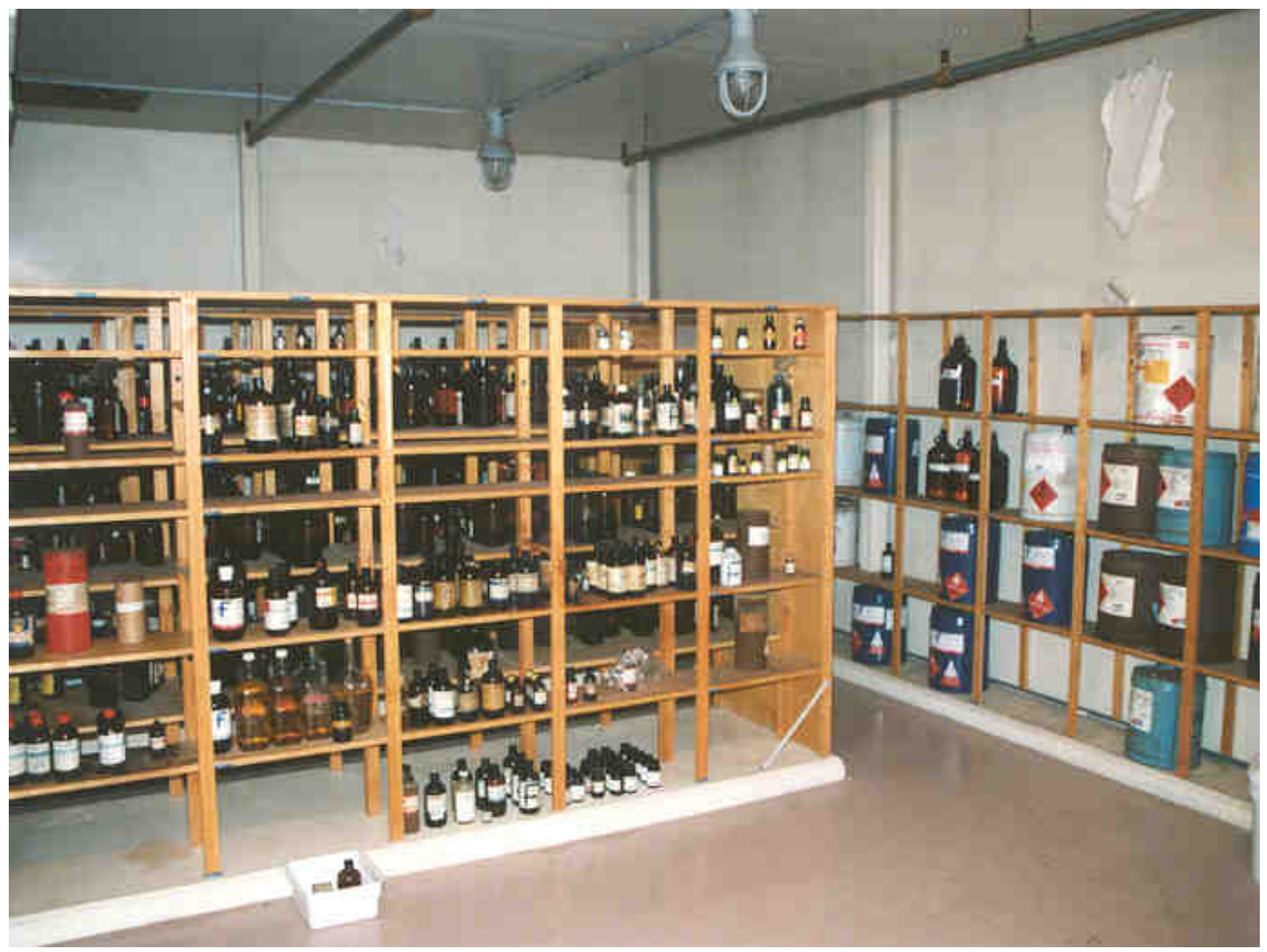

Figure 1. (photo by Ken Niswonger, Chief Chemist Hazardous Materials Division, Colorado Department of Public Health and Environment) Storage of chemicals on wooden shelves. Are any chemicals stored here oxidizers? Note the flammable liquid loading on the right. This shelving arrangement would not last should a fire occur even with fire sprinkler activation. 


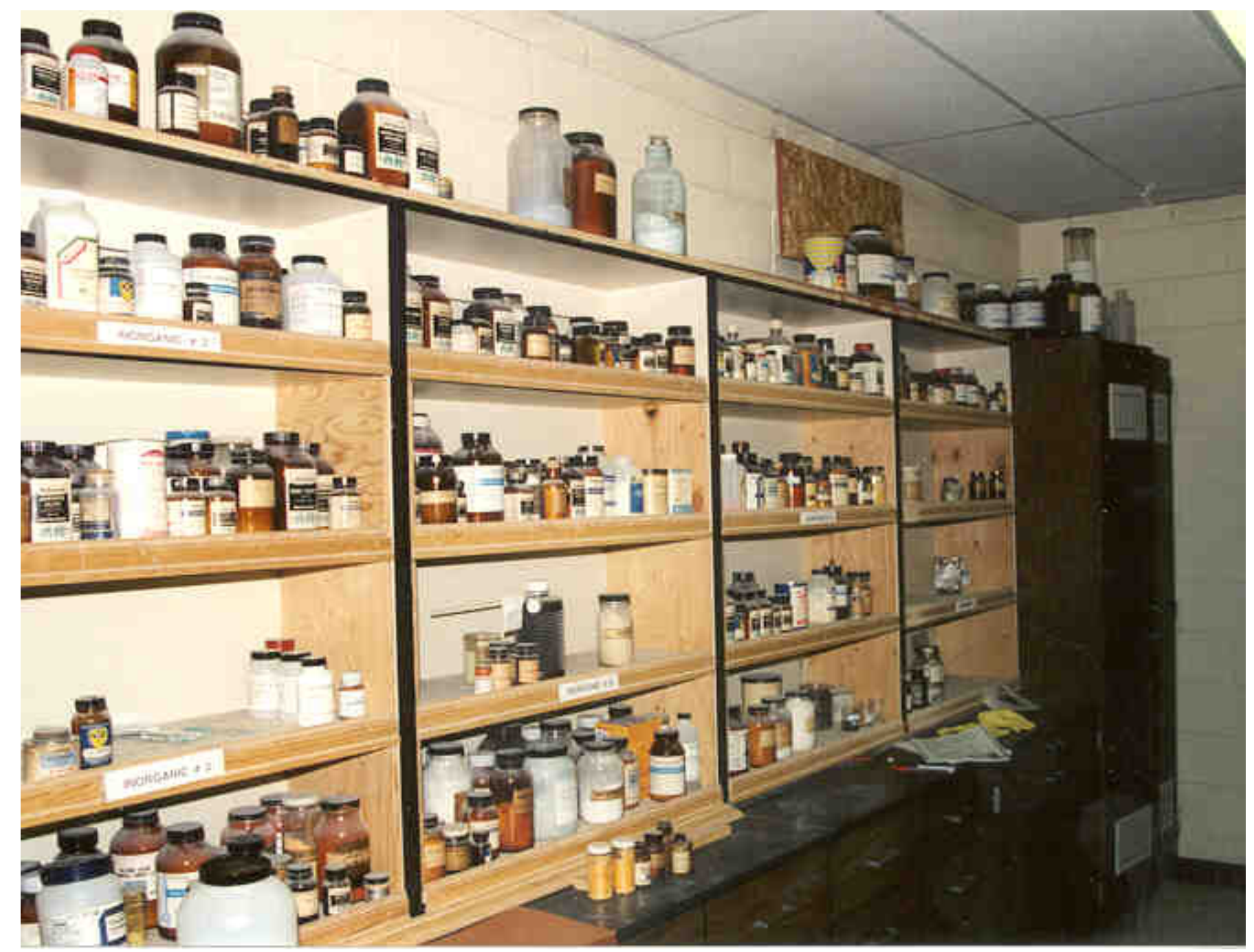

Figure 2. (photo by Ken Niswonger) Chemicals stored above face level. Many chemicals are stored above face level have the potential for spilling into a worker's face during their removal or placement on the shelf. Some chemicals shown on the upper shelves have ground glass or cork stoppers. One should note the good practice of having a lip on chemical storage shelves to protect from containers falling off from vibrations due to seismic activity, road traffic, building work, etc. 


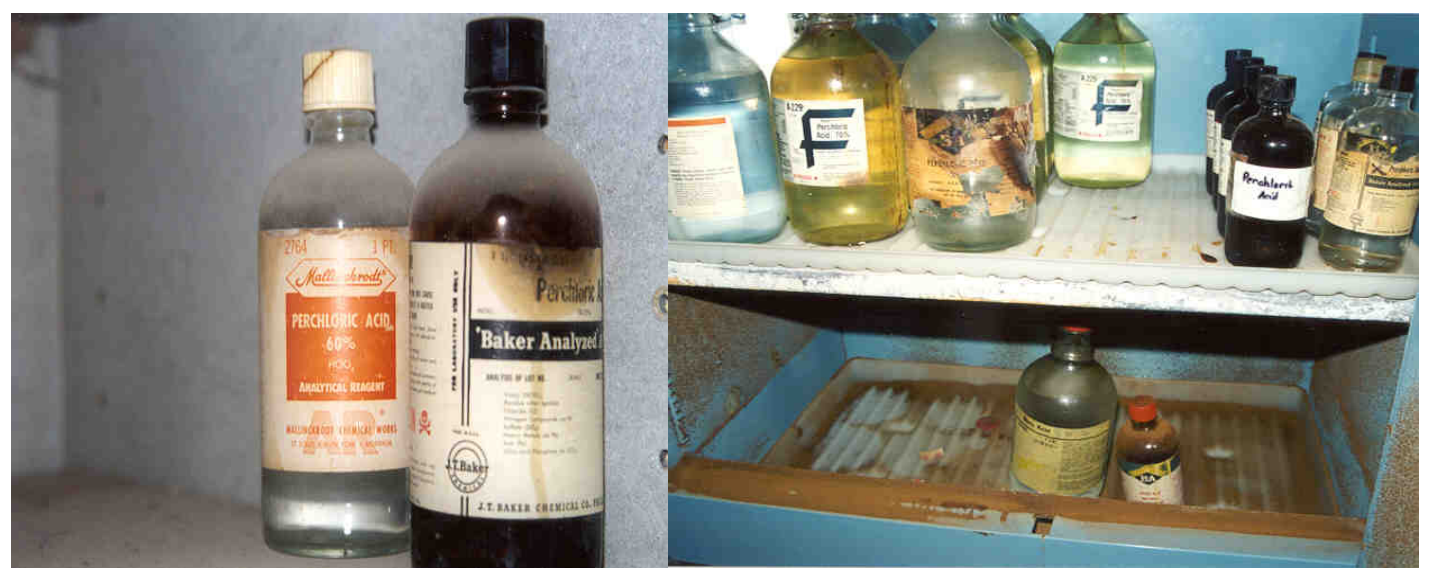

Figure 3. (photos by Ken Niswonger) Storage of Acids in Cabinets. Perchloric acid stored in a cabinet designed for acids (left) shows no corrosion while perchloric acid stored in a metal cabinet (right) shows extensive corrosion even when stored in a plastic secondary container and the metal is painted. Note the cracked cap on the container (right).

\section{Maintenance}

Another issue that is rarely discussed is the need to control those activities performed in a storage area. Because chemical storage areas are inherently unsafe, all activities to be performed there must be reviewed for safety. This means that activities such as maintenance, building modifications, etc., must all be carefully controlled and reviewed to ensure that these activities can be performed safely.

\section{Chemical Storage Requirements}

There are many requirements that regulate the storage of chemicals. These requirements may come from federal or local governments or may be from consensus standards such as those from the NFPA and the Compressed Gas Association (CGA). These requirements are continuously evolving. For example, the recently revised NFPA 55, Standard for the Storage, Use, and Handling of Compressed Gases and Cryogenic Fluids in Portable and Stationary Containers, Cylinders, and Tanks 2003 Edition, greatly expanded it's scope by including extensive requirements for cryogenic liquids.

\section{Compatible Chemical Storage}

Occasionally, one will hear an argument about how compatible chemical storage is a good idea, but can be taken too far. An example of this argument is how some solid oxidizers, such as nitrates, do not need to be segregated from organics. The argument is that a reaction between nitrates and solid organics will not occur under any condition and that requiring their segregation during storage is not justified. While this may be true from a technical point of view, fire codes, building codes, and various NFPA standards require their segregation. 


\section{$\underline{\text { Facility Limits }}$}

Fire code requires facilities to limit the amount of hazardous material stored there. To meet this requirement each facility is to classify each chemical according to their hazards. Examples of hazards include class 1,2, 3 and 4 oxidizer; toxic; highly toxic, pyrophoric gas; etc. There are approximately forty hazard classifications and a chemical is likely to be classified as having more than one hazard. Fire code limits how many pounds of a liquid or solid and cubic feet of a gas of a given hazard classification that can be stored in a facility. If these limits are exceeded then the local authority having jurisdiction may suspend the facility's occupancy permit until limits are attained. If quantities greater that those listed need to be stored, then specialized structures meeting various building and fire codes can be constructed for that purpose.

\section{$\underline{\text { Security }}$}

Security should be a priority for all chemical storage areas. Security is required and is essential for many reasons.

First, basic chemical inventory and management principles require secured storage. If free access to chemical storage areas is allowed, then users will wander in and out with chemicals and the ability to track and keep an accurate inventory will be lost or made much more difficult. Controls can be put in place to monitor when users remove chemicals, but this can incorporate uncertainty into the chemical management process.

Second, unrestrained access to chemical storage areas can endanger the quality of chemical storage. If personnel are allowed to remove chemicals from a common storage area such as a stockroom and then return them after use, then a question of product quality arises. Incorrect dispensing techniques can result in contaminated or impure chemicals and future users may not want to risk using impure chemicals that could negatively affect their work. This results in opened chemicals accumulating in the storage as fewer users will risk using them. Eventually, these accumulated chemicals must be removed as costly waste.

Third, unrestricted access can result in people placing chemicals in the store room in the wrong, incompatible location, which can increase the danger of an accident in the chemical storage area. Lastly, chemicals represent feedstocks or source materials for illegal activities such as illicit drug manufacturing, bomb making, etc. Unrestricted access can result in pilferage and increased liability. Finally, there are some chemicals which may require increased scrutiny due to other reasons such as being on the Drug Enforcement Administration (DEA) watch list (18) for chemicals used in illegal drug manufacturing. 


\section{Signage}

Signage is an integral part of chemical storage. Signage serves to notify emergency responders and visitors, as well as remind employees of the hazards associated with a particular location. For example, there are specific signage requirements for Compressed Gases $(8,9)$, No Smoking signs (10 -15), Oxidizers (7), and Flammables (17), as well as those for the NFPA 704 placard.

Recommendations

Is there a cookbook for chemical storage? The answer is no. Safe chemical storage cannot be reduced to a list or chart. Lists and charts are a starting place to be used only to highlight what to a chemist should be the obvious.

First, a strong Chemical Management program that that controls chemicals and chemical products from before acquisition through their entire lifecycle to disposition is required. Only then can the potential issues that may arise during storage have a chance of being clearly identified. Second, an evaluation of the potential interactions between chemicals and between the chemicals and the facilities, and storage conditions must be performed by a team of professionals, at a minimum consisting of Fire Protection Engineering, Safety Engineering, and a Chemist. Third, from these evaluations policy and procedure must be developed that are clear and concise. Next, chemical compatibility classifications for the entire facility or organization must be documented where they can be easily and quickly accessed. The classifications must also be clear with little chance for confusion or ambiguity and workers trained on the compatibility classification scheme. Lastly, management support must be visible to the workers and unwavering in its commitment.

\section{Conclusion}

Compatible chemical storage is a complex and demanding task that is impacted by regulations, chemical properties, storage conditions and chemical reactivities. This complexity is so great that one can rely on simple solutions for small simple applications. Larger storage applications require a more complex approach that include individually evaluating each chemical for its proper storage condition, control over the storage area, and implementing a unambiguous chemical storage scheme that is readily communicated to all employees. 


\section{References}

1) U.S. Chemical Safety and Hazard Investigation Board, "Hazard Investigation: Improving Reactive Hazard Management," Report No. 2001-01-H, NTIS No. PB2002108795, CSB, Washington, DC (Dec. 2002).

2) Department of Energy Chemical Safety Topical Committee, "Recommendations for Addressing Recurring Chemical Incidents at the U.S. Department of Energy" (May 2005)

3) U.S. Coast Guard, "Cargo Compatibility Chart and Chemical Hazards Response Information System (CHRIS)" accessed at http://www.chrismanual.com/Intro/compatib.htm

4) Environmental Protection Agency, "A Method for Determining the Compatibility of Hazardous Wastes", April 1980. (NTIS / PB80-221005) accessed at http://rehs.rutgers.edu/lswaste epa.chem.htm

5) National Oceanic and Atmospheric Administration, "Chemical Reactivity Worksheet" accessed at http://response.restoration.noaa.gov/type subtopic entry.php?RECORD KEY(entry sub topic type $)=$ entry id,subtopic id,type id\&entry id(entry subtopic type $)=333 \&$ subtopic id(entry subtopic type $)=3 \&$ type id(entry subtopic type $)=3$

6) American Chemical Society, 1990, "Safety in Academic Laboratories"

7) National Fire Protection Association, "NFPA 432 Code for the Storage of Organic Peroxide Formulations", 2002 Edition

8) Compressed Gas Association, CGA P1, Safe Handling of Compressed Gases in Containers, Section 3.7.1

9) National Fire Protection Association, NFPA 55, Standard for the Storage, Use, and Handling of Compressed Gases and Cryogenic Fluids in Portable and Stationary Containers, Cylinders, and Tanks, 2003 Edition, Section 6.13.1

10) Compressed Gas Association, CGA G1, Acetylene, Section 4.2.9

11) Compressed Gas Association, CGA P1, Safe Handling of Compressed Gases in Containers, Section 4.2.1.5

12) National Fire Protection Association, NFPA 55, Standard for the Storage, Use, and Handling of Compressed Gases and Cryogenic Fluids in Portable and Stationary Containers, Cylinders, and Tanks, 2003 Edition, Section 6.13.2.2 
13) National Fire Protection Association, NFPA 55, Standard for the Storage, Use, and Handling of Compressed Gases and Cryogenic Fluids in Portable and Stationary

Containers, Cylinders, and Tanks, 2003 Edition, Section 7.1.1

14) National Fire Protection Association, NFPA 55, Standard for the Storage, Use, and Handling of Compressed Gases and Cryogenic Fluids in Portable and Stationary

Containers, Cylinders, and Tanks, 2003 Edition, Section 7.6.3.2

15) 29CFR1910.253, Oxygen-Fuel Gas Welding and Cutting, B3(I)

16) National Fire Protection Association, NFPA 430, Code for the Storage of Liquid and Solid Oxidizers, Section 2.2.1

17) National Fire Protection Association, NFPA 30, Flammable and Combustible Liquids Code

18) DEA Chemical Control Watch List, Controlled Substances Act.

19) Urben, P. G., “States Matter”, Chem. Hlth. Safety, 2001, 8(6) 35 